\title{
The Practical Application and Innovation of Electronic Commerce in Hotel Management
}

Zeng Tang and Zhang Yuan

Jiangxi applied engineering vocational college.

Jiangxi applied engineering vocational college.

Keywords: E-Commerce; Hotel Management; Practical Application; Innovation

\begin{abstract}
With the rapid progress of electronic information technology, the development of e-commerce has become faster and faster. If we combine e-commerce with hotel management, the future development space is huge. Therefore, this paper takes the practical application of e-commerce and hotel management as the starting point, analyzing the basic elements of e-commerce operation in hotel management, providing corresponding suggestions on the future development and innovation of e-commerce in hotel management.
\end{abstract}

\section{The Influencing Factors of the E-Commerce Application in Hotel Management}

\section{Idea Factor}

The correctness of ideas and whether they are consistent with the development of market economy all affect the practical application of e-commerce in hotel management. At present, there are three main factors that influence and hinder e-commerce in domestic hotel management. First, from senior management point of view, the hotel profits are usually obtained through services. If hotel management wants to develop rapidly, service is the only way. Therefore, e-commerce tends to be ignored. In fact, e-commerce belongs to the latest model in hotel management, and many senior management do not realize the high value of e-commerce itself. At last, it is very difficult for e-commerce to achieve high returns in the short term. Many senior management has lost the short-term interest due to the lack of recognition of the real role of e-commerce.

\section{Talent and Technical Factors}

To ensure the best operation effect of e-business in hotel management, there is a great connection with talents and the advanced equipment. It can be said that technology and talents are the core factors of hotel management and e-commerce integration. This can be seen from the following points. First, hotels should introduce advanced equipment and sophisticated talents in combination with their own situation. Otherwise, it may cause a lot of trouble to the daily operation of the hotel, which will be detrimental to the expansion and future development of the hotel, and even the final management may abandon the use of e-commerce. Second, network technology is developing faster and faster, but there are many problems. Many managers tend to magnify the problem, which leads to the greater limitation of future e-business in hotel management. Finally, the hotel management itself has certain risks in the use of e-commerce. For example, network itself may causes all kinds of problems in room reservation, senior management may be very skeptical about this, which leads to the further development and expansion of e-commerce.

\section{Capital and Cost Management Factors.}

Financial support is the most crucial link in the fast and smooth operation of e-commerce. First, it requires technical equipment and professionals to establish a website for hotel management, and management and maintenance is also indispensable. The basic security of these operations is undoubtedly adequate financial support. Especially for hotels with poor operating conditions, once the e-business system is not qualified or charged too high, it will affect the normal development of other businesses of the enterprise. Once the cost control is unreasonable, in addition with economic development and other problems, it will eventually lead to the decline of hotel efficiency.Because the hotel manager will not consider the e-commerce system with high price, the e-commerce will also become less important, and it may not be used in the hotel operation later. Financial support is a necessary link to ensure efficient operation of the hotel's e-commerce site. We need to build not only the basic website system, but also carry out a lot of publicity and distribution. In this way, the 
influence of e-commerce in the hotel management system can be improved continuously, and the hotel can make more profits.

\section{How to Integrate E-Commerce into Hotel Management Efficiently}

\section{Strengthen Publicity and Promotion}

To complete the prepayment, consumers need to rely on the network platform first, which is the first condition of the combination of e-commerce and hotel management, and it is also the first impression of consumers on the hotel, so that consumers can have a general understanding of the hotel and lay the foundation for future services. At present, many hotels and banks have launched long-term cooperation. However, the consumption concept of some consumers is relatively traditional, hotel must carry out a lot of publicity in the process of specific operation and pay attention to the protection measures of network security.

\section{Cultivate Professional E-Business Skills Talents}

No matter what kind of enterprise, talent is the best driving force for development. Therefore, to apply e-commerce to hotel management better, a group of high-quality e-commerce executives is also a top priority. The hotels should actively guide and absorb the e-commerce talents during the process of the actual operation of e-commerce. In this way, the hotels can guarantee high returns and achieve the initial strategic development plan. In the specific operation, we can start from the following points. First, we should evaluate the current development of the hotel comprehensively to find the defects therein, and actively introduce professional talents with high technical quality to ensure the maximum utility value of human resources and realize the initial planning of e-commerce. Second, the electronic commerce application of the hotel should be precisely positioned, and the division of labor should be clear to different positions, which enables managers have a better grasp of the hotel e-commerce situation and guides new people to grow quickly. Finally, we should carry out regular training, the hotel can invite experts to carry out professional lectures and encourage the hotel e-business personnel to actively participate in the training and increase the opportunities for learning and communication. In this way, the all-round e-commerce management talents can be cultivated to ensure the best effect of e-commerce in hotel management.

\section{Integrate Resources Reasonably and Grasp Hotel Positioning.}

The core of e-commerce is not only a website, but also the integration of all departments of the hotel, making each department play its best value and potential. The hotels must combine their own situation through Intranet and outer net in the process of building the e-commerce system. The integration of hotel business should gradually realize informatization and systematization. Besides, we should play the advantages of the Internet fully and deliver the hotel's business information to the consumer. Therefore, when creating a hotel e-commerce system, the first big problem to solve is positioning. The final goal and requirements should be planned and determined, and then the advantage platform technology of e-commerce will be used to build. In the process of combining e-commerce with hotel management, both advantages and disadvantages exist simultaneously. The two sides should use their respective advantages to complement each other so that the ultimate profit goal of the hotel can be realized.

\section{Adding Hotel Service Items}

The advantages of e-commerce can be brought into full play, which will bring great help to the long-term operation and development of the hotel. It can be better demonstrated from external development. In addition, internal development is indispensable, and the hotel should increase the relevant service items according to the actual situation and consumer demand. While achieving accuracy and punctuality, the service technology content should be gradually improved to meet the demands of consumers and bring the greatest attraction to consumers. During the process of operation, we can start mainly from these points: First, consumers can evaluate hotel services through the Internet. According to the evaluation results, the project with the best operation and the most consumer reaction problems are selected to make reasonable adjustments to meet the demands of consumers. Second, it is necessary to summarize the deficiencies in the work timely and understand the problems in the development process of the hotel, and find the most reasonable 
solution, so that the network can better serve the hotel management. Finally, when propagating in hometown, we should combine the actual situation of the hotel and don't expand too much to ensure that the hotel services can be truly in place. Every consumer can enjoy the best service and finally bring profits to hotel.

\section{Research on Hotel Management Innovation Based on E-Commerce}

\section{Strengthen Client's Research and Development.}

At present, the development of domestic hotel e-commerce model is accelerating, and the software system of consumers is updated very quickly to meet the increasing demands of customers. Therefore, it is necessary to purchase the latest client software in the process of hotel operation such as the new mode of mobile phone e-commerce, so that consumers can experience better services. In addition, when upgrading and maintaining software, we should pay attention to the actual needs of consumers and create more service modes.

\section{Integrate Marketing Network with Customer Demand Fully}

In the specific operation, we should fully consider the network's own internal and external environmental impact and combine with the specific needs of consumers at the same time, making the hotel service mode satisfy basic needs of consumers and consumers feel the convenience of e-commerce and gradually change their views, and even feel a sense of belonging. In this way, the long-term development of the hotel will be greatly beneficial.

\section{To Improve Network Technology through Employee Training}

All staff of the hotel must understand the development of e-commerce and the future trend and be familiar with the application of e-commerce in hotel management. Only the staff related skills have been improved, and the quality of the hotel has been strengthened, and the overall management level of the hotel can achieve substantial development. In addition, we need to conduct network technical training for some employees, which will bring more development space for the hotel's future e-commerce application.

Through the above-mentioned description, the hotel industry must fully understand the value of e-commerce itself and integrate the e-commerce into the hotel management with its own development situation, developing a practical management system to improve the relevant standards of the hotel, providing customers with all kinds of quality services to ensure the long-term development of the hotel and the expansion of the scale.

\section{Reference}

[1] $\mathrm{Xu}$ rongan .exploration of hotel mobile e-commerce platform construction [ $\mathrm{J}$ ].Journal of kaifeng institute of education, 2014, (3).

[2] Wang huijuan. Discussion on the application of e-commerce in China's hotel management [ J ] . Market modernization, 2014, ( 3).

[3] Wang shuhua. The application and development of electronic commerce in the hotel industry [J] . Journal of Liaoning teachers' College (Natural science version) , 2006, ( 3) .

[4] Yu D, Peng L. When does Inferring Reputation Probability Countervail Temptation in Cooperative Behaviors for the Prisoners' Dilemma Game? [J]. Chaos, Solitons \& Fractals, 2015, 78: 238-244.

[5] N. Prieto, ó. López-Campos, J.L. Aalhus, M.E.R. Dugan, M. Juárez and B. Uttaro: Meat Science, Vol. 98 (2014) No.2, p.279.

[6] M. Pla, P. Hernández, B. Ari?o, J.A. Ramírez and Isabel Díaz: Food Chemistry, Vol. 100 (2007) No.1, p.165.

[7] R.R. Pullanagari, I.J. Yule and M. Agnew: Meat Science, Vol. 100 (2015), p.156.

[8] Saudland, A., Wagner, J., Nielsen, J. P., Munck, L., N?rgaard, L. and Engelsen, S. B: Applied Spectroscopy, Vol. 54 (2000) No.3, p.413. 